\title{
МЕЖДУНАРОДНО-ПРАВОВОЕ РЕГУЛИРОВАНИЕ ИСПОЛЬЗОВАНИЯ ЧАСТНЫХ ВОЕННЫХ И ОХРАННЫХ КОМПАНИЙ ЕС В СОВМЕСТНЫХ ОПЕРАЦИЯХ
}

\begin{abstract}
Аннотация: Европейский Союз лишь недавно выработал возможности для участия на мирвоой арене в качестве самостоятельного субъекта обеспечения безопасности. В 1992 годы были приняты Петерсбергские Задания, которые стали основой общей полтики обороны и безопасности(бывщей европейской политики обороны и безопасности), предусматривающей возможность примения военных сил не только в целях проведения гуманитрных операций, но и активных миротворческих, которые могут подразумевать активное участие в боевых действия с армиями иных государств или повстанщескими формированиями. В месте с тем, Европейский союз не обошел один из основных современных трендов в области безопаснотсти и обороны, а именно приватизация и делегирование на контрактной основе ряда функиий, которые традиционо считались прирогативой военнослужаших. Одной из характернь черт этого тренда является использование частных военных и охранных компаний. В статье автор исследуеет применимость норм международного права военных конфликтов и прав человека к действиям и формированиям Европейского союза. Проводится анализ ряда актов ЕС в области оборонь и безопасности. Автор приходит к выводу о том, Европейский Союз хоть и не является государством или международной организацией в чистом виде, обязан соблюдать общепризнаные нормы междунароного гуманитнрого права. Внутрение акты ЕС устанавливают еще больший стандарт соблюдения международного права. Однако, в тоже время, необходимо отметить, что, несмотря на то, что деятельность частных военных и охранных компаний в миссиях ЕС поддается общему правовому регулированию, внутрениие акты ЕС сконструированы таким способом, чтобы максимально снизить возможную ответственность ЕС за их противоправные действия.
\end{abstract}

Ключевые слова: частные военные компании, международное право, международное гуманитрное право, право прав человека, Европейский Союз, ОПОБ, совместные военные операции, совместные военные миссии, правовое регулирование, ответственность.

E вропейский Союз, хоть и всего лишь недавно выработавший общую политику обороны и безопасности, является одним из основных игроков на международной арене и обладает мощными вооруженными силами и принимал участие во многих международных миротворческих и иных операциях в частности в Чаде, Конго, Косово, Македонии и других.

Однако армии европейских государств не обошел стороной доминирующий в современной политике тренд на сокращение военных расходов, что, в купе с необходимостью сохранения военного присутствия, а так же сохранения влияния на бывшие колонии, привело к приватизации ряда функций, которые традиционно считались исключительной прерогативой государственных вооруженных сил. Что, в частности, выразилось в использовании частных военных и охранных компаний.
Основные принципы, в соответствии с которыми ЕС осуществляет свою политику обороны и безопасности, были изложены в Петерсбергских заданиях(Petersberg tasks) ${ }^{1}$, впоследствии положения указанного договора были интегрированы в конституционную систему $\mathrm{EC}^{2}$, даже немного расширив их. Так, в частности, страны ЕС могли использовать силы для пост-конфликтной стабилизации, предотвращения вооруженных конфликтов, оказание военной помощи, в том числе консультационного характера и т.д.(ст.43).

Ввиду общей политики и правовой системы действующей в странах Европейского союза, огромная

\footnotetext{
Petersberg Declaration of the Western European Union Council of Ministers, Bonn, 19 june 1992 http://www.weu.int/ documents/920619peten.pdf

2 Consolidated Version of the Treaty of European Union, OJ 2010 C 83/13.
} 


\section{Национальная безопасность - № 4(33) • 2014}

роль придается соответствию программных документов в области обеспечению обороны и безопасности общеевропейским стандартам соблюдения прав человека и соответствие их международному праву.

В данной статье мы проанализируем, насколько нормы международного гуманитарного права и права прав человека интегрированы в доктрину общей обороны и безопасности Европейского союза, а так же определить правовое положение частных военных и охранных компаний в рамках проводимых ЕС военных и иных операций.

Международные организаций связанны существующим международным правом, что было установлено Судом $\mathrm{OOH}^{3}$. Однако Европейски Союз не совсем подпадает под определение международной организации, так что релевантность данного решения в отношении ЕС находилась под сомнением до 1998 года, когда Суд Европейского Союза вынес решение, согласно которому, органы власти Европейского Союза связанны существующим международным правом в осуществлении своих властных полномочий, данные международные нормы являются одним из источников права $\mathrm{EC}^{4}$.

Так же необходимо отметить, что нормы международного права не просто являются одним из источников права ЕС, но и имеют прямое действие, то есть ЕС и его страны при осуществлении совместной политики в области обороны и безопасности обязаны руководствоваться установленными международным правом стандартам независимо от того, были ли они непосредственно инкорпорированы в руководящие документы $\mathrm{EC}^{5}$. При этом обязаны руководствоваться им независимо оттого, кто является объектом данной политики страна член ЕС или нет ${ }^{6}$.

Так же по мимо норм общего международного права ЕС при проведении международных военных операций связан международными договорами, в которых является подписантом. Так, в частности, Европейский Союз является участником Европейской

3 ICJ, Interpretation of the Agreement of 25 march 1951 between WTO and Egypt, Advisory opinion, ICJ Report, 1980, para.37.

4 ECR, Rake v.Hauptzollant Mainz, ECR I3655, Case C-162/96, 1998.

5 ECR, Criminal Proceeding against Maria Pupino, ECR I-5285, Case C 105/03, para.58.

6 Blockmans S. The European Union and Crisis Management: Policy and Legal Aspects, Hague, 2008, p.375-388; Defeis E. Human Rights and the European Court of Justice: An Appraisal// Fordham Journal of International Law, 31, pp.1104-1117. конвенции о защите прав и основных свобод человека, что говорит о возможной ответственности ЕС при проведении военных операций за противоправные действия сотрудников частных военных и охранных компаний как в случае если странны члены ЕС выступают нанимателями ${ }^{7}$, так и в случае если ЧВОК, нанятые третьей стороной(международной организацией или НГО) действуют на территории, подконтрольной $\mathrm{EC}^{8}$.

Несмотря на то, что Европейский Союз связан нормами права прав человека, большая часть его политики по обеспечению прав человека связана с вниманием к состоянию прав человека в третьих странах, нежели в самом ЕС. Однако, в последнее время наметилась серьезная тенденция по приведению стандартов по обеспечению обороны и безопасности со стандартами в области прав человека9

Так в частности, требования по соблюдению прав детей, женщин и иных защищаемых международным правом лиц используются при оценке планов операций. Так же необходимо отметить, что ЕС предъявляет определенные требования не только к кадровым военнослужащим или госслужащим в целом, но и к лицам, работающим в зоне конфликта на основании контракта, что выражается во включении условий о соблюдений вышеуказанным положений в контракт в качестве основных условий и прохождении необходимых тренировок. Более конкретные нормы права прав человека были имплементированы в концепты операций(CONOPS), планы операций(OPLAN) и правила ведения боя $(\mathrm{ROE})^{10}$.

Однако, необходимо заметить, как это было бы не прискорбно, что какие бы то ни было обязательства о соблюдении прав человека не включены в Договора о

\footnotetext{
Саврыга К.П. Ответственность государства нанимателя за противоправные действия сотрудников частных военных и охранных компаний// Московский журнал международного права №4, 2013, сc.70-88; Bryden A., Caparini M. Private Actors and Security Governance, Verlag, 2006, p.293.

8 Саврыга К.П. Ответственность принимающего государства и государства места инкорпорации за противоправные действия частных военных и охранных компаний// Право и политика, 2014, №1,cc.42-52; Tonkin H. State Control over Private Military and Security Companies in Armed Conflict (Cambridge Studies in International and Comparative Law).Cambridge, 2013, p.149.

9 Pajuste T. Mainstreaming Human Rights in the Context of the European Security and Defense Policy, The Erik Castren Institute Research Report n.23/2008, 2008.

10 Naert F. International Peace Operations and International Humanitarian Law, Oxford, p.61.
} 
статусе вооруженных сил(SOFA) и Договора о статусе миссий(SOMA), единственным намеком на обязанность их соблюдать можно обнаружить в стандартной статье, включаемой в подавляющее большинство подобных договоров, это положение, обязывающее соблюдать право принимающего государства и воздерживаться от поступков, идущих в разрез с целями миссии ${ }^{11}$. Но необходимо заметить, что, несмотря на то, что данное положение слишком общее, что бы подразумевать необходимость воздерживаться от любых нарушений прав человека, нужно сказать, что если в отношении военнослужащих стран членов ЕC, участвующих в миссии существуют иные механизмы защиты. То в отношении сотрудников работающих по контракту, как ЧВОК, данные договора не распространяются, а доступные средства защиты слишком ограничены. Особенно учитывая, что сотрудники, нанятые в стране проведения операции, всегда исключаются из сферы действия соглашения, а практика субподряда среди ЧВОК достаточно распространена ${ }^{12}$. Что сильно сказывается на возможности привлечение к ответственности не только преступников, но ЕС за несоблюдение требований по контролю за ЧВОК и обязательств должной осмотрительности, что особенно важно в вопросе получения компенсаций. Учитывая уже имевшую место, скандальную вовлеченность сотрудников ЧВОК в работорговлю на территории бывшей Югославии ${ }^{13}$.

Так же необходимо отметить, что, как правило, в операциях, проводимых в последнее время, участвуют подразделения основной целью которых является мониторинг соблюдения прав человека на территории конфликта как со стороны командированного

11 Agreement between the European Union and the Republic of Chad on the Status of EU-led forces in the Republic of Chad, 6 march 2008, OJ 2008 L83/40; Agreement between European Union and Central African Republic on the Status of EU-led forces in the Central African Republic, 16 april 2008, OJ 2008 L 136/46; Agreement between the European Union and Georgia on the status of Monitoring Mission in Georgia, OJ 2008 L 311/31; Agreement between the European Union and the Somali Republic on the status of EU-led naval forces in the Somali Republic in the framework of the EU military operation Atlanta, 15 january 2009, OJ 2009 L 10/29.

12 Небольсина М.А. Частные военные и охранные компании в Ираке и Афганистане: аспекты деятельности и механизмы контроля // Ежегодник ИМИ.2011 cс.288-307.

13 Maffai M., Accountability for Private Military and Security Companies Employees that Engage in Sex Trafficking and Related Abuses While under Contract with the United States Overseas, Wisconsin International Law Journal, 09, 2008, p.1095. контингента, так и местных властей, выступающих в союзе с экспедиционными силами ${ }^{14}$. Однако в тоже самое время необходимо отметить, что, несмотря на достаточно широкий круг полномочий и спектр деятельности, ни один рапорт не включал в себя мониторинг деятельности ЧВОК ${ }^{15}$.

Нужно отметить, что наряду с операциями в большинстве своем полицейского характера, ряд видов деятельности, в которых могут участвовать силы ЕС это боевые операции по разрешению кризиса, включая миротворческие(ст.43(1)), которые подразумевают относительно крупномасштабные военные действия против организованных сил государства или повстанцев на территории третьей страны, а так же то факт, что данное соглашение предусматривает основание и способы использования силы государствами членами ЕС для самообороны ${ }^{16}$, ставит нас перед вопрос об инкорпорации норм международного гуманитарного права или права военных конфликтов в систему регулирования общей политики безопасности и обороны.

Так как силы Союза принимали участие в достаточно большом количестве военных операций: Конкордия(Македония), Алтея(Босния и Герцеговина), EUFOR Tchad $\backslash$ RCA, EUFOR RG CONGO и т.д. При этом, если в случае с Республиками бывшей Югославии и Конго, силы ЕС действовали уже в пост-конфликтной ситуаций, когда основные боевые действия уже закончились, то в случае с конфликтом в Чаде и операцией Артемис, силам ЕС было дано разрешение на применение военной силы для достижения целей мандата за пределами мер необходимых для самообороны.

Одно из основных препятствий на пути применения норм jus in bello является тот факт, что EC не является стороной подписантом международных соглашений, которые в данном случае открыты для подписания тлько государствами. Однако данная проблема была разрешена Европейским Судом в деле Intertanko ${ }^{17}$, постановив, что для ЕС обязательны не

14 Council of the EU, ESDP Presidency Report on ESDP, Doc 10748/09, Brussels, 2009, para.89.

15 Francioni F., Ronzitti N. War by Contract: Human Rights, Humanitarian Law and Private Contractors, Oxford, 2011, p.307.

16 Kielmansegg von S.G. The Meaning of Petersberg: Some Considerations on the Legal Scope of the ESDP Operations // CML Review, 2007, №44, p.648.

17 ECJ, The Queen v. Security of State for Transport, Case C-308/06, 2008, para.51. 


\section{Национальная безопасность - № 4(33) • 2014}

только общепризнанные нормы международного права(customary international law), но и нормы общего международного права(general international law), а так же договоры, которые можно рассматривать как кодификацию оных, в категорию которых попадает большая часть норм международного права военных конфликтов. Однако, в тоже самое время возникает ряд проблем, так если страны европейского союза связанны одними и теми же международными договорами в области международного права военных конфликтов, а через них ими связан и ЕС, то ряд стран, с которыми ЕС проводил совместные операции не являются подписантами этих соглашений(как Турция и Марокко). В данных случаях, нормы, применимые к силам ЕС распространяются на вооруженные силы этих стран, в силу Решения совета ЕС и их решения о присоединении к мандату, так же нужно заметить, что таким образом на них распространяется соглашение о статусе сил. Но все же нужно отметить, что все они исключают из сферы своей деятельности сотрудников нанятых по контракту в стране базирования, независимо от того, представляют ли их контрактные обязанности непосредственное участие в военных действиях или нет, а большая часть соглашений исключает и международных сотрудников ЧВОК ${ }^{18}$.

Несмотря на наличие норм международного права, регулирующих вопросы вооруженных конфликтов и соблюдения прав человека. Нам необходимо рассмотреть, насколько данные нормы были непосредственно инкорпорированы во внутренние акты Европейского Союза. Так будучи частью внутреннего правого регулирования они имеют более простые механизмы надзора, контроля и ответственности.

Среди таких инструментов правового регулирования особо выделяются Инструкции ЕС по соблюдению международного гуманитарного права ${ }^{19}$. Так первая часть данной инструкции резюмирует существуюее правовое регулирования военных операций, в то время как вторая устанавливает требования для третьих стран-участниц совместных операций в части соблюдения права вооруженных конфликтов и их участия в мониторинге.

Так же необходимо упомянуть прикладные инструменты, такие как Инструкция по защите гражданских лиц в проводимых ЕС военных опе-

18 См.13, p.314.

19 EU Guidelines on Promoting Compliance with International Humanitarian Law, OJ 2005 C 327/4. рация ${ }^{20}$ и Стандарты поведения Единой политики обороны и безопасности при проведении военных операций ${ }^{21}$. Данные инструкции устанавливают основное регулирование правового поля для объединенных сил ЕС во время проведения операций. Так в частности, особое внимание уделяется тщательной подготовке сотрудников по вопросам прав человека, международного гуманитарного права и обеспечению безопасности гражданских лиц в зонах конфликтов. В тоже самое время, Стандарты проведения являются одним из важных документов, на основании которого принимаются решения при планировании военных операций и выражают приверженность релевантным нормам международного права. Так же необходимо отметить, что рассекреченные документы, в частности план операции OPLAN EUPOL AFGANISTAN ${ }^{22}$, явно свидетельствует о том, что обязательства по соблюдению международного права и национального законодательства Афганистана(в том случае если оно не противоречит нормам международного права) являлось обязательным для членов миссии.

Усиление роли ЧВОК в деятельности вооруженных сил стран членов Европейского Союза, признанное на официальном уровне ${ }^{23}$, делает необходимым определение правового режима, в рамках которого сотрудники частных военных и охранных компаний осуществляют свою деятельность, которая чаще всего проходит в зонах международных и внутренних вооруженных конфликтов. Нарушение нормы международного права военных конфликтов и права прав человека, в той части, в которой они признаны международным сообществом, обязательны для ЧВОК, однако это мало дает в плане непосредственного соблюдения данных норм сотрудниками ЧВОК. В связи с чем, приобретает особую значимость инкорпорирование данных норм во внутренний правовой порядок Европейского Союза. В данной статье нами было показано, что нормы международного гуманитарного права и права прав человека являются тем правовым режимом, в рамках которого строиться

20 Draft Guidelines on Protection of Civilians in EU-led Crisis Management Operations, Council Doc.14805/03, 2003.

21 Generic Standard of Behavior for ESDP Operations, Council Secretariat Doc.8373/3/05 rev 3 annex, 2005.

22 OPLAN for the EUPOL Afghanistan Police Mission, Council Doc. $10132 / 33$.

23 European Defense Agency, Future Trends from the Capability Developments Plan, 2008, para.53. 
общая политика безопасности и обороны, а так же приводятся в действие конкретные планы операций.

Что же касается сотрудников частных военных компаний, то необходимо добавить, что, так как они не могут обладать статусом комбатанта ${ }^{24}$, так как не было зафиксировано случая, когда страны ЕС инкорпорировали ЧВОК в свои вооруженные силы de jure или de facto, в отличие, например, от США или Саудовской Аравии, а значит, являются гражданскими лицами. А значит ЕС или его страны, участвующие в операции могут нести ответствен- ность за деятельность ЧВОК только в случае, если они действовали по их указаниям, инструкциям или если во время совершения противоправных действия над ними осуществлялся эффективный контроль. Сознательное исключение сотрудников нанятых по контракту от требований, предъявляемых соглашениями о статусе миссии и сил, говорит о желании ЕС и государств членов максимально освободиться от ответственности за их проитвоправные деяния. Что же касается применения силы, то ее осуществление возможно лишь в рамках самообороны.

\section{Библиография:}

1. Petersberg Declaration of the Western European Union Council of Ministers, Bonn, 19 june 1992.

2. Consolidated Version of the Treaty of European Union, OJ 2010 C 83/13.

3. ICJ, Interpretation of the Agreement of 25 march 1951 between WTO and Egypt, Advisory opinion, ICJ Report, 1980.

4. ECR, Rake v.Hauptzollant Mainz, ECR I3655, Case C-162/96, 1998.

5. ECR, Criminal Proceeding against Maria Pupino, ECR I-5285, Case C 105/03.

6. Blockmans S. The European Union and Crisis Management: Policy and Legal Aspects, Hague, 2008, p.375-388; Defeis E. Human Rights and the European Court of Justice: An Appraisal//Fordham Journal of International Law, 31.

7. Саврыга К.П. Ответственность государства нанимателя за противоправные действия сотрудников частных военных и охранных компаний// Московский журнал международного права №4, 2013.

8. Bryden A., Caparini M. Private Actors and Security Governance, Verlag, 2006.

9. Саврыга К.П. Ответственность принимающего государства и государства места инкорпорации за противоправные действия частных военных и охранных компаний// Право и политика, 2014, №1.

10. Pajuste T. Mainstreaming Human Rights in the Context of the European Security and Defense Policy, The Erik Castren Institute Research Report n.23/2008, 2008.

11. Naert F. International Peace Operations and International Humanitarian Law, Oxford, 2006.

12. Agreement between the European Union and the Republic of Chad on the Status of EU-led forces in the Republic of Chad, 6 march 2008, OJ 2008 L83/40.

13. Agreement between European Union and Central African Republic on the Status of EU-led forces in the Central African Republic, 16 april 2008, OJ 2008 L 136/46.

14. Agreement between the European Union and Georgia on the status of Monitoring Mission in Georgia, OJ 2008 L $311 / 31$.

15. Agreement between the European Union and the Somali Republic on the status of EU-led naval forces in the Somali Republic in the framework of the EU military operation Atlanta, 15 january 2009, OJ 2009 L 10/29.

16. Небольсина М.А. Частные военные и охранные компании в Ираке и Афганистане: аспекты деятельности и механизмы контроля // Ежегодник ИМИ.2011.

17. Council of the EU, ESDP Presidency Report on ESDP, Doc 10748/09, Brussels, 2009.

18. Francioni F., Ronzitti N. War by Contract: Human Rights, Humanitarian Law and Private Contractors, Oxford, 2011.

19. Kielmansegg von S.G. The Meaning of Petersberg: Some Considerations on the Legal Scope of the ESDP Operations // CML Review, 2007, №44.

24 Cameron L. and Chetail V. Privatizing War: Private Military and Security Companies under Public International Law, Cambridge. 2013, pp. 386-431. 


\section{Национальная безопасность - № 4(33) • 2014}

20. ECJ, The Queen v. Security of State for Transport, Case C-308/06, 2008.

21. EU Guidelines on Promoting Compliance with International Humanitarian Law, OJ 2005 C 327/4.

22. Draft Guidelines on Protection of Civilians in EU-led Crisis Management Operations, Council Doc.14805/03, 2003.

23. Generic Standard of Behavior for ESDP Operations, Council Secretariat Doc.8373/3/05 rev 3 annex, 2005.

24. OPLAN for the EUPOL Afghanistan Police Mission, Council Doc.10132/33.

25. European Defense Agency, Future Trends from the Capability Developments Plan, 2008.

26. Cameron L. and Chetail V. Privatizing War: Private Military and Security Companies under Public International Law,.Cambridge. 2013.

27. Maffai M., Accountability for Private Military and Security Companies Employees that Engage in Sex Trafficking and Related Abuses While under Contract with the United States Overseas, Wisconsin International Law Journal, 09, 2008.

28. Tonkin H.State Control over Private Military and Security Companies in Armed Conflict (Cambridge Studies in International and Comparative Law).Cambridge, 2013.

29. Е.В. Постникова Эволюция правового регулирования свободы предоставления услуг в Европейском Союзе // Международное право и международные организации / International Law and International Organizations. - 2012. - 4. - C. 93-111.

30. Саврыга К.П. Частные военные и охранные компании по международному праву // Международное право и международные организации / International Law and International Organizations. - 2013. - 4. - С. 456-464. DOI: 10.7256/2226-6305.2013.4.10098.

31. Сазонова К.Л.. Международно-правовые аспекты и вопросы ответственности при привлечении частных военных и охранных предприятий к осуществлению миротворческих операций ООН.. // Право и политика. - 2014. - № 4. - С. 477-485. DOI: 10.7256/1811-9018.2014.4.1135

32. Афанасьев В.В.. Современные локальные конфликты. // Международные отношения. - 2014. - № 1. C. 56-61. DOI: 10.7256/2305-560X.2014.1.10061

33. Трунов И.Л.. Правовое регулирование частных военных компаний .// Административное и муниципальное право. - 2013. - № 11. - С. 1070-1073. DOI: 10.7256/1999-2807.2013.11.967

\section{References:}

1. Petersberg Declaration of the Western European Union Council of Ministers, Bonn, 19 june 1992.

2. Consolidated Version of the Treaty of European Union, OJ 2010 C 83/13.

3. ICJ, Interpretation of the Agreement of 25 march 1951 between WTO and Egypt, Advisory opinion, ICJ Report, 1980.

4. ECR, Rake v.Hauptzollant Mainz, ECR I3655, Case C-162/96, 1998.

5. ECR, Criminal Proceeding against Maria Pupino, ECR I-5285, Case C 105/03.

6. Blockmans S. The European Union and Crisis Management: Policy and Legal Aspects, Hague, 2008, p.375-388; Defeis E. Human Rights and the European Court of Justice: An Appraisal//Fordham Journal of International Law, 31.

7. Savryga K.P. Otvetstvennost' gosudarstva nanimatelya za protivopravnye deistviya sotrudnikov chastnykh voennykh i okhrannykh kompanii// Moskovskii zhurnal mezhdunarodnogo prava №4, 2013.

8. Bryden A., Caparini M. Private Actors and Security Governance, Verlag, 2006.

9. Savryga K.P. Otvetstvennost' prinimayushchego gosudarstva i gosudarstva mesta inkorporatsii za protivopravnye deistviya chastnykh voennykh i okhrannykh kompanii// Pravo i politika, 2014, №1.

10. Pajuste T. Mainstreaming Human Rights in the Context of the European Security and Defense Policy, The Erik Castren Institute Research Report n.23/2008, 2008.

11. Naert F. International Peace Operations and International Humanitarian Law, Oxford, 2006.

12. Agreement between the European Union and the Republic of Chad on the Status of EU-led forces in the Republic of Chad, 6 march 2008, OJ 2008 L83/40.

13. Agreement between European Union and Central African Republic on the Status of EU-led forces in the Central African Republic, 16 april 2008, OJ 2008 L 136/46. 
14. Agreement between the European Union and Georgia on the status of Monitoring Mission in Georgia, OJ 2008 L $311 / 31$.

15. Agreement between the European Union and the Somali Republic on the status of EU-led naval forces in the Somali Republic in the framework of the EU military operation Atlanta, 15 january 2009, OJ 2009 L 10/29.

16. Nebol'sina M.A. Chastnye voennye i okhrannye kompanii v Irake i Afganistane: aspekty deyatel'nosti i mekhanizmy kontrolya // Ezhegodnik IMI.2011.

17. Council of the EU, ESDP Presidency Report on ESDP, Doc 10748/09, Brussels, 2009.

18. Francioni F., Ronzitti N. War by Contract: Human Rights, Humanitarian Law and Private Contractors, Oxford, 2011.

19. Kielmansegg von S.G. The Meaning of Petersberg: Some Considerations on the Legal Scope of the ESDP Operations // CML Review, 2007, №44.

20. ECJ, The Queen v. Security of State for Transport, Case C-308/06, 2008.

21. EU Guidelines on Promoting Compliance with International Humanitarian Law, OJ 2005 C 327/4.

22. Draft Guidelines on Protection of Civilians in EU-led Crisis Management Operations, Council Doc.14805/03, 2003.

23. Generic Standard of Behavior for ESDP Operations, Council Secretariat Doc.8373/3/05 rev 3 annex, 2005.

24. OPLAN for the EUPOL Afghanistan Police Mission, Council Doc.10132/33.

25. European Defense Agency, Future Trends from the Capability Developments Plan, 2008.

26. Cameron L. and Chetail V. Privatizing War: Private Military and Security Companies under Public International Law,.Cambridge. 2013.

27. Maffai M., Accountability for Private Military and Security Companies Employees that Engage in Sex Trafficking and Related Abuses While under Contract with the United States Overseas, Wisconsin International Law Journal, 09, 2008.

28. Tonkin H.State Control over Private Military and Security Companies in Armed Conflict (Cambridge Studies in International and Comparative Law).Cambridge, 2013.

29. E.V. Postnikova Evolyutsiya pravovogo regulirovaniya svobody predostavleniya uslug v Evropeiskom Soyuze // Mezhdunarodnoe pravo i mezhdunarodnye organizatsii / International Law and International Organizations. 2012. - 4. - S. 93-111.

30. Savryga K.P. Chastnye voennye i okhrannye kompanii po mezhdunarodnomu pravu // Mezhdunarodnoe pravo i mezhdunarodnye organizatsii / International Law and International Organizations. - 2013. - 4. - S. 456-464. DOI: 10.7256/2226-6305.2013.4.10098.

31. Sazonova K.L.. Mezhdunarodno-pravovye aspekty i voprosy otvetstvennosti pri privlechenii chastnykh voennykh i okhrannykh predpriyatii k osushchestvleniyu mirotvorcheskikh operatsii OON.. // Pravo i politika. - 2014. № 4. - S. 477-485. DOI: 10.7256/1811-9018.2014.4.1135

32. Afanas'ev V.V.. Sovremennye lokal'nye konflikty. // Mezhdunarodnye otnosheniya. - 2014. - № 1. - S. 56-61. DOI: 10.7256/2305-560X.2014.1.10061

33. Trunov I.L.. Pravovoe regulirovanie chastnykh voennykh kompanii . // Administrativnoe i munitsipal'noe pravo. - 2013. - № 11. - S. 1070-1073. DOI: 10.7256/1999-2807.2013.11.967 